\title{
KOMUNIKASI FATIS DALAM TALK SHOW SAWAKO NO ASA
}

\section{Edi Sutrisno}

\author{
312201400500@mhs.dinus.ac.id \\ Universitas Dian Nuswantoro
}

\begin{abstract}
This study discusses the form of phatic expression and also phatic communication function analyzed based on the phatic theory by Jakobson. The objective of this study is to find out the variation of Japanese phatic expression and phatic communication function in Sawako no Asa Talk Show. The data this study analyses come from Sawako no Asa Talk Show and the research method used is descriptive qualitative. The speeches in the talk show are analyzed using Jakobson theory of Phatic and Communication Function theory by Jumanto. The result of the study found that the forms of Phatic were based on particles, words, phrases in the form of small talk. Phatic communication were used to maintain or reaffirm communication in the talk show. The researcher hope that this study can give reference to other studies in the future, especially studies regarding Phatic Communication in order to create or maintain social relationships. This study in many ways is still lacking, the researcher hope that there will be further studies towards this subject matter.
\end{abstract}

Keywords: Language Function, Phatic Function, Phatic Communication Function

Fungsi bahasa secara umum adalah sebagai alat untuk melakukan komunikasi antarindividu maupun antarkelompok. Menurut Jakobson dalam artikel dengan judul closing statement: linguistics and poetics yang dimuat dalam T. Sebeok (1964) menjelaskan fungsi bahasa dibagi menjadi enam yaitu fungsi referensial, fungsi ekspresif/motif, fungsi konatif, fungsi fatis, fungsi puitik, dan fungsi metabahasa. Di antara ke enam fungsi tersebut fungsi fatis menjadi sorotan utama bagi peneliti sebagai dasar penelitian setelah melihat fenomena yang terjadi. Misalnya dalam mengucapkan salam "selamat pagi", apakah hanya sebagai salam atau ada tujuan lain dibalik pengucapan salam "selamat pagi" tersebut. Komunikasi fatis sering dipakai dalam suatu komunikasi maupun interaksi dengan mitra bicara ungkapan fatis sering muncul tanpa disadari. Dengan ungkapan fatis inilah komunikasi interaksi dapat berjalan dengan enak, santai dan harmonis.

*)Artikel Skripsi Fakultas IImu Budaya Universitas Dian Nuswantoro 
Istilah fatis bermula dari teori Malinowski (1923) yang mengeluarkan tipe tuturan baru atau lebih dikenal dengan phatic communion. Tuturan ini berfungsi untuk memunculkan atau menciptakan ikatan sosial yang harmonis dengan tujuan saling bertukar kata-kata. Konsep Malinowski tentang phatic communion ini dilanjutkan oleh Roman Jakobson dengan dasar model organon Bühler $(1916,1990)$ yang menghasilkan fungsi bahasa menjadi enam seperti yang telah disebutkan. Klasifikasi dari Jakobson inilah yang mengilhami Leech (1977) dan menghasilkan fungsi bahasa menjadi lima yaitu fungsi informatif, fungsi ekspresif, fungsi direktif, fungsi estetis, fungsi fatis. Dari sini Biber (1999) juga mengelompokkan bentukbentuk yang mirip dengan ungkapan fatis, Biber menyebutnya dengan selipan (insert). Di sini Biber mengungkapkan selipan ada sebelas jenis yaitu interjeksi, salam dan perpisahan, pemarkah wacana, tanda minta perhatian, pemancing respon, respon, peragu, terima kasih, pemarkah kesopanan, permintaan maaf, kata seru.

Ungkapan fatis sendiri jika ditelaah secara gramatikal dan struktural dianggap kurang mumpuni. Ungkapan fatis jika dihadapkan dengan situasi yang berbeda maknanya kemungkinan terbalik bahkan berbeda. Pengkajian ungkapan fatis secara struktural dianggap kurang memadai jika dihadapkan dengan apa yang disebut dengan konteks. Dalam pengkajian ini konteks sangatlah berperan penting diibaratkan seperti ruh. Pengkajian ini lebih dikenal dalam dunia linguistik dengan istilah pragmatik. Pragmatik merupakan makna yang timbul dalam interaksi yaitu makna yang dihasilkan sebagai suatu proses yang dinamis, yang mencakup negosiasi makna antara penutur dan petutur yang disesuaikan dengan konteks baik itu konteks fisik, konteks sosial, dan konteks linguistik serta ada potensi makna dari ujaran (Thomas dalam Jumanto, 2017:41).

Ungkapan fatis ditentukan berdasarkan kriteria kefatisan teori Roman Jakobson sedangkan fungsi fatis ditentukan berdasarkan konteks yang telah diutarakan oleh Monica Crabtree dan Joyce Powers tentang konteks sebagai pengetahuan latar. Ungkapan fatis sering digunakan dalam dalam percakapan sehari hari misalnya dalam acara talkshow, film, dan lain-lain terutama percakapan yang bersifat casual speech. Acara talk show dipilih sebagai sumber data karena percakapannya lebih natural dibandingkan dengan film yang mengikuti skenario dari 
Edi Sutrisno, Komunikasi Fatis dalam Talk Show Sawako no Asa

penulis. Talk show yang dipakai pada penelitian ini yaitu acara Sawako no Asa dari TBS TV. Penelitian ini memberikan gambaran ungkapan fatis yang ada dalam talk show tersebut dan mendeskripsikan fungsi fatis yang digunakan dalam isi talk show tersebut.

Penelitian ini menggunakan metode deskriptif kualitatif yang mempunyai maksud untuk memaparkan wujud fatis dalam acara talk show dan memberi gambaran tentang fungsi fatis. Bentuk fatis banyak dijumpai ketika melakukan percakapan baik formal maupun tidak formal. Contohnya tuturan "selamat malam" merupakan contoh ungkapan fatis yang mempunyai fungsi memulai percakapan. Selain memulai percakapan "selamat malam" mempunyai fungsi lain misalnya mengungkapkan kesantunan dan lain-lain. Konteks di sini mempunyai peranan yang kuat dalam menentukan fungsinya. Peneliti menggunakan teori kefatisan dari Jakobson karena dianggap peneliti lebih lengkap dan memenuhi dalam penelitian ini jika dibandingkan dengan teori Malinowski dan Geofrey Leech tentang fungsi fatis. Dalam bahasa Jepang penelitian tentang fatis sangat sedikit oleh karena itu peneliti melakukan penelitian ini. Hasil penelitian ini bisa menambah pengetahuan tentang fungsi fatis. Berdasarkan wujud tuturan yang digunakan dalam acara Sawako no Asa ditemukan rumusan masalah dari hasil pengamatan secara seksama selama proses penelitian. Percakapan talk show yang menghasilkan tuturan yang dapat diamati dengan teori dan metode yang digunakan untuk menganalisis.

\section{METODE}

Penelitian ini menggunakan metode deskriptif kualitatif. Data penelitian kualitatif berbentuk narasi cerita, petuturan informan, dokumen-dokumen pribadi yang berbentuk foto, catatan pribadi atau harian, perilaku, gerak tubuh, mimik, dan lain sebagainya yang tidak didominasi angka-angka sebagaimana penelitian kualitatif (Idrus, 2009:25). Sedangkan deskriptif sendiri merupakan ciri dari penelitian kualitatif. Menurut Moleong (2014:11) deskriptif yaitu data yang terkumpul dan berupa kata-kata, gambar, dan bukan angka. Sumber data diambil dari talk show 
sawako no asa yang ditayangkan di TBS tv Jepang. Peneliti menyimak video talk show dicatat tuturannya kemudian menandai ungkapan fatis kemudian dimasukkan ke dalam kategorisasi dan dianalis. Kemudian dimasukkan ke dalam fungsi komunikatif fatis.

\section{HASIL DAN PEMBAHASAN}

\section{Untuk Mempertahankan atau mengukuhkan Komunikasi}

Berikut ini merupakan data yang menunjukkan fungsi komunikasi fatis yang berfungsi untuk mempertahankan atau mengukuhkan komunikasi dengan tujuan untuk menjaga agar percakapan tetap berlangsung:

Data 1: SA/S2/02:59-03:06

(1)まさみ：前に, 映画の撮影でずっと鼻声だったってことがあって。

Masami : mae ni,eiga no satsuei de zutto hanakoe datta tte koto ga atte.

: 'sebelumya, selama shooting film pernah menggunakan suara

hidung ( suara sengau dari hidung)'.

佐和子：へええ、なんていう映画ですか？

Sawako : heee, nante in eigadesuka?

: 'heee, film apa itu?'

まさみ : 『タッチ』っていう映画なんですけど。

Masami : tachi tte iueiga nandesukedo

: 'judulnya tachi'.

(Sawako no Asa, menit 02, detik 59)

Pada data percakapan SA/S2/02:59 - 03:06 percakapan antara Masami dengan Sawako dapat dianalisis yakni Masami sebagai Addresser (pengirim pesan) dapat ditunjukkan dengan tuturan Masami 前に, 映画の撮影でずっと鼻声だった つてことがあって“mae ni,eiga no satsuei de zutto hanakoe datta tte koto ga atte” sebelumya, selama shooting film pernah menggunakan suara hidung (suara sengau dari hidung) yang merupakan suatu pernyataan tentang dirinya yang pernah shooting dengan suara dari hidung (suara sengau). Sawako sebagai Addressee (penerima 
Edi Sutrisno, Komunikasi Fatis dalam Talk Show Sawako no Asa

pesan), hal ini dapat ditunjukkan dengan respon Sawako yang ada dalam tuturan heee, nante iu eigadesuka?. Respon terkejut sekaligus untuk jeda akan bertanya kembali kepada Masami. Message yang dibawa Masami yaitu tentang dirinya yang sebelumnya bermain dalam sebuah film dengan kondisi suara hidung (sengau). Context di sini yakni cerita Masami sebelum pada waktu bermain film Taachi dia menggunakan suara sengau sepanjang proses shooting film yang berjudul Tachi. Code yang digunakan baik Masami maupun Sawako sama yaitu bahasa verbal yakni bahasa Jepang. Contact terjadi antara Masami dengan tuturan mae ni,eiga no satsuei de zutto hanakoe datta tte koto ga atte dan direspon Masami dengan respon terkejut dengan tuturan heee, nante iu eigadesuka? “ film apa itu”, Tuturan hee (intonasi naik) di sini mempunyai makna terkejut atas pernyataan Masami sebelumnya yang menandakan adanya hubungan yang menyambungkan tuturan Masami mae ni,eiga no satsuei de zutto hanakoe datta tte koto ga atte "sebelumya, selama shooting film pernah menggunakan suara hidung (suara sengau dari hidung)". Tuturan hee merupakan ungkapan fatis yang dimaksudkan untuk mempertahankan dan mengukuhkan komunikasi.

Komunikasi fatis yang ditunjukkan dengan ungkapan (1) 几ええ、(2) なん ていう映画ですか?. heee, nante iu eigadesuka? ” Hee film apa itu?”. Kata heee di sini menekankan ungkapan Sawako sebagai tanda terkejut mendengar tuturan Masami. Tuturan hee dilanjutkan Sawako dengan mempertanyakan nante iu eigadesuka? "film apa itu" sebagai upaya Sawako untuk menjaga agar percakapan tetap berlangsung.

\section{Untuk Memulai Komunikasi}

Berikut ini merupakan data yang menunjukkan fungsi komunikasi fatis yang berfungsi untuk memulai komunikasi yang mempunyai fungsi komunikatif fatis untuk melakukan basa basi dan untuk mencaiptakan harmoni sebagai berikut:

Data 2: SA/S1/00:25 - 00:31

(2) 佐和子

Sawako
: 朝は出さない主義だそうで。

: asa wa dasanai shugi da sou de 
: pagi ini (kaki) kelihatannya tidak terlihat yah"

まさみ

ないんですけ

Masami
: そうですね、わかんないけど、そう言うことは ど。

: soudesune, wakannai kedo, sou iu koto wa naindesukedo

: "begitu yaa" saya tidak tahu. Yang seperti itu tidak ada

(Sawako no Asa, menit 0 , detik 25 )

Pada data 2 SA/S1/00:25 - 00:31 dapat dilihat bahwa terjadi percakapan antara Sawako dan Masami. Addresser di sini ditunjukkan dengan tuturan Sawako yakni 朝は出さない主義だそうで。asa wa dasanai shugida sou de” pagi ini (kaki) kelihatannya tidak terlihat yaa". Sedangkan Addresse ditunjukkan kepada Masami dengan tuturan そうですね、わかんないけど、そう言うことはないんですけど soudesune, wakannai kedo, sou iu koto wa naindesukedo"begitu yaa" saya tidak tahu. Yang seperti itu tidak ada”. Pesan yang dibawa Sawako yakni tuturan 朝は出さ ない主義だそうで。asa wa dasanai shugida sou de pagi ini kelihatannya tidak terlihat yaa". Message tuturan tersebut adalah Masami yang terkenal dengan kakinya yang lentik pagi ini tidak terlihat. Context percakapan dimulai setelah acara dibuka oleh Sawako setelah itu melakukan obrolan ringan yang mengomentari Masami pada pagi itu. Masami yang terkenal dengan kakinya pada pagi itu tidak terlihat karena memakai celana panjang. Code dalam data 2 menggunakan bahasa Jepang. Hal ini terbukti dengan tuturan 朝は出さない主義だそうで。asa wa dasanai shugida sou de pagi ini(kaki) kelihatannya tidak terlihat yaa dan Masami dengan tuturan そうで すね、わかんないけど、そう言うことはないんですけ soudesune, wakannai kedo, sou iu koto wa naindesukedo"begitu yaa" saya tidak tahu, Yang seperti itu tidak ada”. Keduanya sama menggunakan bahasa Jepang. Contact terjadi antara Sawako dan Masami , bermula dari tuturan Sawako 朝は出さない主義だそうで。asa wa dasanai shugida sou de pagi ini (kaki) kelihatannya tidak terlihat yaa" menyambungkan dengan tuturan そうですね、わかんないけど、そう言うこと はないんですけど soudesune, wakannai kedo, sou iu koto wa naindesukedo"begitu 
Edi Sutrisno, Komunikasi Fatis dalam Talk Show Sawako no Asa

yaa”. Tuturan 朝は出さない主義だそうで。 asa wa dasanai shugida sou de” pagi ini (kaki) kelihatannya tidak terlihat yaa" tuturan tersebut dapat diklasifikasikan sebagai tuturan yang aman dan ringan menurut Jumanto (2017: 169) karena Sawako mengomentari pakaian yang digunakan Masami . Tuturan Sawako tersebut dimaksudkan untuk memulai komunikasi dengan melakukan percakapan yang ringan dan aman.

Komunikasi fatis yang ditunjukkan dengan kata (1) 朝は出さない主義だそ うで。 asa wa dasanai shugida sou de pagi ini (kaki) kelihatannya tidak terlihat yaa", (2)そうですね、わかんないけど、soudesune, wakannai kedo, “begitu yaa” “saya tidak tahu”. Tuturan pertama 朝は出さない主義だそうで。asa wa dasanai shugida sou de pagi ini (kaki) kelihatannya tidak terlihat yaa" bermaksud untuk melakukan percakapan yang ringan yakni percakapan yang mengomentari celana Masami dan aman dengan cara melakukan basa basi untuk memulai percakapan. Tuturan kedua yakni kata そうですね soudesune “begitu yaa” terletak di awal tuturan bermakna membenarkan atau mengukuhkan atas tuturan 朝は出さない主義だそうで。asa wa dasanai shugida sou de pagi ini (kaki) kelihatannya tidak terlihat yaa"yang bertujuan untuk menciptakan harmoni dengan menyelaraskan jawaban dari pertanyaan sebelumnya.

\section{Untuk Menarik Perhatian Mitra Tutur (interlocutor) atau Menjaga Agar Mitra Tutur tetap memperhatikan Petutur.}

Berikut ini merupakan data yang menunjukkan fungsi komunikasi fatis yang berfungsi untuk menarik perhatian mitra tutur (interlocutor) atau menjaga agar mitra tutur tetap memperhatikan petutur dan mempunyai fungsi komunikatif fatis untuk menjaga agar percakapan tetap berlangsung serta menciptakan harmoni terdapat dalam data sebagai berikut:

Data 3 : SA/S3/06:08 - 06:15

(3) 佐和子 : : やあ、お父さんもお母さんもスタイルいいんです か? 
$\begin{array}{ll}\text { Sawako } & \text { : Jaa, otosan mo okasan mo sutairu iindesuka } \\ & : \text { 'nah, perawakan ayah dan ibu bagaimana?' } \\ \text { まさみ } & : \text { そうですね、身長は高い、たか系ですね。 } \\ \text { Masami } & : \text { Soudesune,, shincho wa takai,takakei desune } \\ & : \text { 'begitu ya, badannya tinggi. Keturunan tinggi' }\end{array}$

(Sawako no Asa, menit 06, detik 08)

Pada data 3 percakapan SA/S3/06:08 - 06:15 percakapan antara Sawako dan Masami. Dari percakapan itu dapat dianalisis yakni Sawako sebagai Addresser (pengirim pesan) dapat ditunjukkan dengan tuturan Sawako じやあ、お父さんもお 母さんもスタイルいいんですか? Jaa, otosan mo okasan mo sutairu iindesuka“nah, perawakan ayah dan ibu bagaimana?" yang merupakan pertanyaan kepada Masami tentang kedua orang tuanya. Masami sebagai Addressee (penerima pesan), hal ini dapat ditunjukkan dengan respon atau tuturan そうですね、身長は高 い、たか系ですね Soudesune, shincho wa takai, takakei desune 'begitu ya, badannya tinggi, Keturunan tinggi' yang merupakan pernyataan Masami kepada kedua orang tuanya. Message yang dibawa Sawako yakni pertanyaan tentang perawakan atau bentuk kedua orang tua Masami dapat dilihat dari tuturan じゃあ、 お父さんもお母さんもスタイルいいんですか? Jaa, otosan mo okasan mo sutairu iindesuka“nah, perawakan ayah dan ibu bagaimana?". Context yang terlihat dari pengalihan topik yang dilakukan Sawako sebelumnya, kemudian masuk topik pembicaraan baru tentang kedua orang tua Masami. Membuat topik topik ringan agar dapat menarik perhatian dari Masami. Code dalam percakapan ini menggunakan kode yang sama yakni bahasa Jepang dan sedikit campur kode dengan bahasa inggris yang diserap kedalam bahasa Jepang. Hal ini dibuktikan dengan kata スタイル sutairu"style atau gaya atau perawakan", hal ini dimaksudkan untuk penegasan dari perawakan ayah dan ibunya. Contact di sini terjadi antara Sawako dan Masami, Sawako dengan tuturan じゃあ、お父さんもお母さんもスタイルいいんです か? Jaa, otosan mo okasan mo sutairu iindesuka "nah, perawakan ayah dan ibu 
Edi Sutrisno, Komunikasi Fatis dalam Talk Show Sawako no Asa

bagaimana?" bermaksud mengalihkan topik pembicaraan dengan kata jaa. kemudian dihubungkan dengan dengan tuturan Masami そうですね、身長は高い、たか系で すね Soudesune,, shincho wa takai, takakei desune 'begitu ya, badannya tinggi, Keturunan tinggi' di sinilah terjadi kontak yang membuat fungsi fatis terjadi. Tuturan じゃあ、お父さんもお母さんもスタイルいいんですか? Jaa, otosan mo okasan mo sutairu iindesuka“nah, perawakan ayah dan ibu bagaimana?" dimaksudkan Sawako untuk menarik perhatian mitra tutur dalam hal ini Masami sebagai mitra tutur dalam percakapan ini.

Komunikasi fatis yang ditunjukkan dengan ungkapan (1) じゃあ jaa “nah”, (2)そうですね Soudesune”begitu yaa”. Ungkapan fatis yang pertama じやあ jaa "nah" mempunyai tugas supaya mengalihkan topik pembicaraan untuk menarik mitra tutur dan tetap menjaga agar mitra tutur tetap menjaga percakapan yang tengah berlangsung. Ungkapan fatis yang kedua そうですね Soudesune ”begitu yaa” bertugas untuk mengukuhkan atau membenarkan tuturan じやあ、お父さんもお母 さんもスタイルいいんですか?Jaa, otosan mo okasan mo sutairu iindesuka“nah, perawakan ayah dan ibu bagaimana?" supaya timbul keselarasan untuk menciptakan harmoni.

\section{Untuk Memastikan Berfungsinya Saluran Komunikasi}

Berikut ini merupakan data yang menunjukkan fungsi komunikasi fatis yang berfungsi untuk memastikan berfungsinya saluran komunikasi dan fungsi komunikatis fatis untuk menjaga agar percakapan tetap berlangsung:

Data 4 : SA/S3/05:51 - 06:02

(4) 佐和子 : :おおあああ。。私なんか TBSさんに拾われた時に

Sawako : $\quad$ ooaaa.. watashi nanka TBS san ni hirowaretatokini :ooooaa, saya waktu di rekrut TBS televisi

$\begin{array}{ll}\text { まさみ } & : \underline{\text { はい }} \\ \text { Masami } & : \text { hai } \\ & \text { :iya }\end{array}$


佐和子

Sawako
: まあ、面談みたいな感じだったんですけども。。。 身長いくつ?ってゆわれて、150ですって、あっちつ ちえ、ちっちえ、 ちっちえ!ってゆわれて・・

: Maa, mendai mitai na kanji dattandesukedomo ..shincho ikutsu?? to yuwarete, 150 desutte, ... chihe chice cheee te yuwarete,

: aaaa, serasa dengan muka memelas ,berkata tinggi badan berapa 150, dia berkata kecil kecil kecil..

(Sawako no Asa, menit 05 detik 51)

Pada data 4 SA/S3/05:51 - 06:02 terjadi percakapan antara Sawako dan Masami dapat dianalisis Sawako sebagai pengirim pesan (Addresser) hal ini ditunjukkan denga tuturan Sawako sebagai berikut おおあああ。。私なんか TBS さんに拾われた時に ooaaa.. watashi nanka TBS san ni hirowaretatokini “ooooaa, saya waktu di rekrut TBS televisi”. Tuturan tersebut mempunyai makna proses ketika Sawako bergabung dengan TBS televisi. Addresse di sini Masami sebagai penerima pesan dibuktikan dengan pernyataan はい hai “iya”. Mempunyai maksud mengukuhkan atau membenarkan apa yang tanyakan petutur. Message yang terdapat dalam tuturan Sawako berisi pengalaman Sawako ketika masuk ke TBS televisi. Context percakapan yakni curhatan Sawako ketika masuk TBS television setelah itu diceritakan ketika baru masuk melamar di beri pertanyaan yang sepele yaitu tentang tinggi badan. Code dalam percakapan di sini menggunakan bahasa yang sama yakni bahasa Jepang dapat dibuktikan dengan tuturran berikut おおあああ。。私なん か TBS さんに拾われた時に ooaaa.. watashi nanka TBS san ni hirowaretatokini “ooooaa, saya waktu di rekrut TBS televisi” begitu pula dengan Masami はい hai iya. Contact di sini terjadi antara Sawako dan Masami, Sawako dengan tuturan おおああ あ。私なんか TBS さんに拾われた時に ooaaa.. watashi nanka TBS san ni hirowaretatokini “ooooaa, saya waktu di rekrut TBS televisi” tuturan ini bermaksud menginformasikan sesuatu kepada Masami. Kemudian tuturan ini dihubungkan 
Edi Sutrisno, Komunikasi Fatis dalam Talk Show Sawako no Asa

dengan tuturan Masami はい hai iya tuturan Masami bermaksud mengukuhkan atau memebenarkan tuturan sebelumnya. Kemudian disambung dengan tuturan Sawako yang mengkokohkan tuturan sebelumnya dengan tuturan まあ、面談みたいな感じ だったんですけども。。。身長いくつ?ってゆわれて、150ですって、あっ ちつちえ、ちつちえ、ちつちえ!つてゆわれて・Maa, mendai mitai na kanji dattandesukedomo ..shincho ikutsu?? to yuwarete, 150 desutte, ...aa chihe chice cheee te yuwarete,, "aaaa, berasa dengan muka memelas ,berkata tinggi badan berapa 150,,aaa dia berkata kecil kecil kecil”. Ungkapan fatis はい hai “iya” bertugas untuk memastikan berfungsinya saluran komunikasi.

Komunikasi fatis yang ditunjukkan dengan ungkapan (1) はい hai, (2)まあ Maa aaa. Ungkapan fatis pertama yakni はい hai “iya” untuk mengukuhkan atau membenarkan apa yang di tanyakan maupun dinyatakan mitra tutur. Tuturan ini bertujuan menjaga agar percakapan tetap berlangsung. Ungkapan fatis kedua まあ Maa" aaa". Bertugas untuk menghindari kesenyapan ketika sedang berbicara karena tuturan maa terletak diawal kalimat. Tujuan dari tuturan maa di sini untuk menjaga agar percakapan tetap berlangsung.

\section{Untuk Memutuskan Komunikasi}

Berikut ini merupakan data yang menunjukkan fungsi komunikasi fatis yang berfungsi untuk memutuskan komunikasi:

Data 5 : SA/S3/06:02 - 06:08

(5) 佐和子：なに、この大人とか思って。。。やんなっちやいます。それ はおいといて

Sawako : Nani, kono otona toka omotte.....yan nachaimasu. Sore wa oite ite

: apa, ini laki laki ini, ya sudahlah, mari kita tinggal kan itu

まさみ：はい

Masami : hai

: iya

(Sawako no Asa, menit 06 detik 02) 
Pada data 5 : SA/S3/06:02 - 06:08 percakapan antara Sawako dan Masami dapat dianalisis Sawako sebagai pengirim pesan (Addresser) hal ini ditunjukkan denga tuturan Sawako sebagai berikut なに、この大人とか思って。。。やんなっ ちやいます。それはおいといて Nani, kono otona toka omotte.....yan nachaimasu. Sore wa oite ite "apa, ini laki laki ini, ya sudahlah ,mari kita tinggal kan itu” tuturan dapat diidentifikasi sebagai pengirim pesan. Addresse di sini Masami sebagai penerima pesan dibuktikan dengan pernyataan balasan kepada Sawako yakni はい hai "ya" yang merupakan penegasan atas pernyataan sebelunya. Message yang ada dalam percakapan ini ialah mengolok ngolok orang yang telah mewancarai Sawako ketika masuk di TBS. Terlihat dari tuturannya なに、この大人とか思って。。。 やんなっちやいます。それはおいといて Nani, kono otona toka omotte.....yan nachaimasu. Sore wa oite ite "apa, ini laki laki ini, ya sudahlah, mari kita tinggal kan itu". Context di sini dimulai ketika cerita Sawako ketika masuk ke TBS tv. Sawako menceritakan kekita pertama masuk TBS dia diinterview karena punya pengalaman kurang mengenakkan. Code yang dipakai pada percakan ini menggunakan bahasa sama yakni bahasa Jepang. Contact terjadi antara Sawako dan Masami, dimulai dari tuturan Sawako なに、この大人とか思って。。。やんなっちやいます。それは おいといて Nani, kono otona toka omotte.yan nachaimasu. Sore wa oite ite “apa, ini laki laki ini, ya sudahlah, mari kita tinggal kan itu" kemudian dihubungkan dengan tuturan Masami はい hai “ya”. Ungkapan fatis それはおいといて sore wa oite ite” mari kita tinggal kan itu” mempunyai tujuan memutuskan komunikasi secara sementara kemudian disambungkan kembali.

Komunikasi fatis yang ditunjukkan dengan ungkapan (1) それはおいとい て Sore wa oite ite “mari kita tinggal kan itu”(2) はい hai “iya”.ungakapan fatis pertama それはおいといて Sore wa oite ite “mari kita tinggal kan itu” mrupakan tuturan ajakan untuk beralis topik dengan meninggalkan topik pembicaraan itu. Tuturan ini bertujuan untuk memulai percakapan baru dengan mitra tutur.Ungkapan fatis yang kedua はい hai “iya”. Merupakan ungkapan untuk mengukuhkan atau 
Edi Sutrisno, Komunikasi Fatis dalam Talk Show Sawako no Asa membenarkan apa yang ditanyakan lawan bicara. Hal ini digunakan dengan tujuan menjaga agar percakapan tetap berlangsung.

\section{SIMPULAN}

Dari hasil analisis terhadap keseluruhan data di talk show Sawako no Asa ditemukan lima fungsi fatis dalam percakapan. Kelimanya adalah 1) untuk mempertahankan atau mengukuhkan komunikasi; 2) untuk memulai komunikasi; 3) untuk menarik perhatian mitra tutur (interlocutor) atau menjaga agar mitra tutur tetap memperhatikan petutur; 4) untuk memastikan berfungsinya saluran komunikasi; 5) untuk memutuskan komunikasi. Faktor yang dominan dalam penggunaan ungkapan fatis adalah fungsi untuk mempertahankan atau mengukuhkan komunikasi dan yang paling sedikit untuk memutuskan komunikasi

\section{DAFTAR PUSTAKA}

Grice (1991). Logic and Conversation. Harvard University Press.

Jayanti, Septhany. (2010). Partikel Fatis Bahasa Mandarin Dalam Acara Temu WicaraTelevisi Yule Baifenbai Seratus Persen Hiburan. Depok: FIB Universitas Indonesia.

Jakobson, Roman. (1960) 1964. “Closing Statement: Linguistic and poetics.” Dalam Thomas Sebeok (Ed) Style in Language. Cambridge, MA: The MIT Press, halaman 350-377.

Jumanto, Dr. 2008. Komunikasi Fatis di Kalangan Penutur Jati Bahasa Inggris. Semarang :World Pro Publising.

Jumanto. 2014. Phatic Communication: How English native Speakers Create Ties of Union. American Journal of Linguistic

Kridalaksana, Harimurti. 1983. Kamus Linguistik, Penerbit PT.Gramedia, Jakarta. Harimurti. (1986) 1994. Kelas Kata dalam Bahasa Indonesia [edisi kedua], jakarta: PT.Gramedia Pustaka Utama. 
Leech, Geofrey. 1993. Prinsip-Prinsip Pragmatik. Jakarta: Gramedia Pustaka Utama. Levinson, Stephen C (1983). Pragmatics. Cambridge University Press.

Senft, Gunter. 2009. Phatic Communion. Nijmegen: Max Planck Institute for Psycholinguistics.

Saifudin, Akhmad. 2005. Faktor Sosial Budaya dan Kesopanan Orang Jepang dalam Pengungkapan Tindak Tutur Terima Kasih pada Skenario Drama Televisi Beautiful Life Karya Kitagawa Eriko. Thesis. Pascasarjana Kajian Wilayah Jepang Universitas Indonesia.

Saifudin, Akhmad. 2005. Faktor Sosial Budaya dan Kesopanan Orang Jepang dalam Pengungkapan Orei no Kotoba. Laporan Penelitian. Semarang : Universitas Dian Nuswantoro.

Saifudin, Akhmad, Aryanto, Bayu, \& Budi, Iwan Setiya. 2008. Analisis Fungsi Pragmatik Tindak Tutur Pertanyaan dalam Percakapan Bahasa Jepang antara Wisatawan Jepang dan Pemandu Wisata Indonesia di Candi Borobudur. Lite, 4(1), 8-15. http://doi.org/10.5281/zenodo.2636103

Saifudin, Akhmad. 2010. Analisis Pragmatik Variasi Kesantunan Tindak Tutur Terima Kasih Bahasa Jepang dalam Film Beautiful Life Karya Kitagawa Eriko. Lite, 6(2), 172-181. http://doi.org/10.5281/zenodo.2631226

Saifudin, Akhmad. 2018. Konteks dalam Studi Linguistik Pragmatik. LITE, 14(2), 108-117. http://doi.org/10.5281/zenodo.2631204

Sudaryanto. 1993. Metode dan Aneka Teknik Analisis Bahasa: Pengantar Penelitian Wahana Kebudayaan secara Linguistis. Yogyakarta: Duta Wacana University Press.

Waridin. 2008. Ungkapan Fatis dalam Acara Temu Wicara Televisi. Jakarta: FIB Universitas Indonesia.

Yule, George. (1996). Pragmatics. Oxford University Press

Yunita, Metta. 2010. Analisis Penerjemahan Fatis Bahasa Indonesia Dalam bahasa Jepang. Depok: FIB Universitas Indonesia. 